\title{
Cardiac abnormalities in adults with the attenuated form of mucopolysaccharidosis type I
}

\author{
O. I. I. Soliman • R. G. M. Timmermans • \\ A. Nemes $\cdot$ W. B. Vletter $\cdot$ J. H. P. Wilson • \\ F. J. ten Cate $\cdot$ M. L. Geleijnse
}

Received: 17 February 2007 / Submitted in revised form: 11 April 2007 / Accepted: 23 April 2007 /Published online: 14 June 2007

(C) SSIEM and Springer 2007

\begin{abstract}
Summary Background: Cardiac involvement in mucopolysaccharidosis type I (MPS I) has been studied primarily in its most severe forms. Cardiac involvement, particularly left ventricular (LV) systolic and diastolic function, in the attenuated form of MPS I is less well known. Methods: Cardiac function was prospectively investigated in 9 adult patients with the attenuated form of MPS I. All patients underwent 12-lead electrocardiography, $24 \mathrm{~h}$ Holter monitoring and two-dimensional echocardiography including tissue Doppler imaging (TDI). Eighteen age- and sex-matched healthy volunteers served as a control group. Results: Aortic, mitral
\end{abstract}

Communicating editor: Verena Peters

Competing interests: None declared

O. I. I. Soliman · A. Nemes · W. B. Vletter ·

F. J. ten Cate $\cdot$ M. L. Geleijnse

Department of Cardiology, Thoraxcenter,

Erasmus Medical Center, Rotterdam, The Netherlands

R. G. M. Timmermans • J. H. P. Wilson

Department of Internal Medicine, Erasmus Medical Center,

Rotterdam, The Netherlands

O. I. I. Soliman

Department of Cardiology, Al-Hussein University Hospital, Al-Azhar University, Cairo, Egypt

\author{
A. Nemes \\ Second Department of Medicine and Cardiology Center, \\ University of Szeged, Szeged, Hungary \\ M. L. Geleijnse $(\bowtie)$ \\ Thoraxcenter, Room BA 304, Erasmus Medical Center, \\ Dr Molewaterplein 40, 3015 GD Rotterdam, \\ The Netherlands \\ e-mail: m.geleijnse@erasmusmc.nl
}

and tricuspid valve thickening was seen in, respectively, $5(56 \%), 4(44 \%)$ and $2(22 \%)$ patients. Moderate mitral valve stenosis was seen in 1 patient and moderate aortic stenosis in 2 patients. All patients had mild-to-moderate aortic and mitral valve regurgitation and 6 patients $(67 \%)$ had mild-to-moderate tricuspid valve regurgitation. Despite normal LV dimensions, ejection fraction and mass index, MPS patients had lower mean systolic mitral annular velocities $(6.1 \pm 0.6$ vs $9.1 \pm 1.4 \mathrm{~cm} / \mathrm{s}, p<0.01)$ compared to normal control subjects. Similarly, mean early diastolic mitral annular velocities were lower in MPS patients $(7.8 \pm 0.9$ vs $13.3 \pm 3.3 \mathrm{~cm} / \mathrm{s}, p<0.01)$. Conclusion: MPS I patients with the attenuated phenotype have not only valvular abnormalities but also LV diastolic and systolic abnormalities.

$\begin{array}{ll}\text { Abbreviations } \\ \text { Em } & \text { mitral annular peak early diastolic velocity } \\ \text { GAGs } & \text { glycosaminoglycans } \\ \alpha \text {-IDUA } & \alpha \text {-L-iduronidase } \\ \text { LV } & \text { left ventricular } \\ \text { MPS } & \text { mucopolysaccharidosis } \\ \text { Sm } & \text { mitral annular peak systolic velocity } \\ \text { TDI } & \text { tissue Doppler imaging }\end{array}$

\section{Introduction}

Mucopolysaccharidosis type I (MPS I) is a rare autosomal recessive disease caused by deficiency of the lysosomal enzyme $\alpha$-L-iduronidase ( $\alpha$-IDUA). This enzyme is involved in the degradation of sulfated glycosaminoglycans (GAGs) and deficiency results in intracellular accumulations of the GAGs heparin 
sulfate and dermatan sulfate (Neufeld and Muenzer 2001). Deficiency of $\alpha$-IDUA gives rise to three main classical clinical entities-Hurler syndrome, presenting in infancy and the most severe phenotype; Hurler-Scheie syndrome, a phenotype presenting in childhood of intermediate severity; and Scheie syndrome, the mildest form of MPS I. Because of the great overlap between patient groups (which cannot be distinguished by either enzyme deficiency or urinary GAGs), it may be more appropriate to categorize the patients into attenuated and severe forms of MPS I (Vijay and Wraith 2005). Cardiomyopathy and thickening of cardiac valves and large vessels have been described in MPS I patients, especially in the most severe form (Braunlin et al 2006a,b; Dangel 1998; Nelson et al 1990). Cardiac involvement in the attenuated form of MPS I is less well known. We therefore prospectively studied cardiac involvement in a series of patients with the attenuated form of MPS I.

\section{Methods}

\section{Study population}

A standard programme was initiated to prospectively investigate cardiac involvement and function in 9 adult patients with the attenuated form of MPS I who were not treated with enzyme replacement therapy or bone marrow or cord blood transplantation. The diagnosis of MPS I was based on demonstrating a deficiency of $\alpha$-IDUA activity in cultured fibroblasts together with increased urinary levels of GAGs. All patients gave informed consent before participating into the study, which included clinical assessment, 12-lead electrocardiography, Holter monitoring and two-dimensional echocardiography including tissue Doppler imaging (TDI).

\section{Two-dimensional echocardiography}

Echocardiographic studies were performed with a Sonos 7500 ultrasound system (Philips, Best, The Netherlands) equipped with an S3 transducer (frequency 1-3.2 MHz) by a single, experienced sonographer (W.B.V.). Images were sent digitally to a remote workstation with EnConcert software (Philips) for offline analysis. Cardiac dimensions and Doppler parameters were measured using electronic callipers and computed by preinstalled standard formulae.

Valvular anatomy and function

For assessment of valvular thickness, fundamental imaging at a frequency of $2-3 \mathrm{MHz}$ was used with a zoom function applied to the valve region and optimal gain settings. Based on normal values for mitral and aortic valve leaflet thickness (ranging from 0.7 to 3.0 and from 0.7 to $2.0 \mathrm{~mm}$, respectively) (Crawford and Roldan 2001; Weissman et al 1994), abnormal valve leaflet thickness was defined as a thickness $>3.0 \mathrm{~mm}$ for the mitral valve or $>2.0 \mathrm{~mm}$ for the aortic valve. Valvular peak and mean gradients were calculated from the continuous-wave Doppler transvalvular velocities using the Bernoulli equation (Otto 2004). Valvular regurgitation was graded as absent, mild, moderate or severe on a semi-quantitative scale using standard colour Doppler and continuous-wave Doppler parameters according to the recommendations of the American Society of Echocardiography (Zoghbi et al 2003).

\section{Cardiac dimensions}

For better endocardial border definition, secondharmonic imaging was used (transmitted frequency 1.6 MHz, received frequency $3.2 \mathrm{MHz}$ ). Assessment of left atrial dimension, left ventricular (LV) wall thickness, LV end-diastolic and end-systolic dimensions and LV mass index was done as described before (Vydt et al 2007).

\section{LV systolic function}

Non-foreshortened apical 2- and 4-chamber views were used for assessment of LV end-diastolic and end-systolic volumes. LV ejection fraction was calculated by the modified bi-plane Simpson according to the recommendations of the American Society of Echocardiography (Cheitlin et al 1997; Lang et al 2006). In addition, systolic mitral (Sm) annular peak velocities were measured with TDI from the inferoseptal and anterolateral wall. Subsequently, mean Sm (calculated from these two walls) was calculated. Normal values for LV ejection fraction and mean Sm were derived from 18 age- and sex-matched volunteers with normal left atrial and LV dimensions and LV function as described before (Nikitin et al 2003). The normal lower cut-off value (mean-SD) for LV ejection fraction was $50 \%$ and for mean $\mathrm{Sm}$ was $7.7 \mathrm{~cm} / \mathrm{s}$.

\section{LV diastolic function}

The assessment of LV diastolic function was based on a combination of end-expiratory pulsed-wave Doppler mitral inflow velocity, pulmonary venous flow and mitral annular TDI recordings, according to the recommendations of the American Society of 
Echocardiography (Khouri et al 2004). To measure pulsed-wave Doppler mitral inflow velocities, a sample volume was placed at the tips of the mitral leaflets with a minimized angle between mitral inflow and the Doppler beam. From the velocity tracing obtained, peak early diastolic transmitral flow velocity $(E)$, peak late diastolic transmitral flow velocity (A), early filling deceleration time (DT), and A-wave duration were measured. To measure pulmonary flow velocities, a sample volume was placed at the right paraseptal pulmonary vein in the apical 4-chamber view. Systolic (S) and early diastolic (D) velocities and the duration of late atrial reversed (AR) diastolic flow were measured. TDI was applied in the pulsed-wave Doppler mode at the level of the mitral annulus in an apical 4-chamber view. From the velocity tracing obtained, the inferoseptal and anterolateral early diastolic mitral (Em) annular peak velocities were measured. Subsequently, mean Em (calculated from these two walls) and the dimensionless ratio of early mitral inflow peak velocity to early mitral annular peak diastolic velocity $(\mathrm{E} / \mathrm{Em})$ were calculated. All described measurements were averaged from 3 samples.

Based on these three methods, normal LV diastolic function was defined as a combination of E/A ratio between 0.75 and 1.50 , DT between 150 and $220 \mathrm{~ms}$, pulmonary $\mathrm{S}>\mathrm{D}, \mathrm{AR}$ duration $<\mathrm{A}$-wave duration $+30 \mathrm{~ms}$, mean $\mathrm{Em}>10.0 \mathrm{~cm} / \mathrm{s}$, and $\mathrm{E} / \mathrm{Em}<9$. Stage I diastolic dysfunction (impaired LV relaxation) was defined as E/A ratio $<0.75$ and DT $>220 \mathrm{~ms}$. Stage II diastolic dysfunction (pseudo-normal LV filling) was defined as an E/A ratio between 0.75 and 1.5 with a mean $E m<7 \mathrm{~cm} / \mathrm{s}$ and $\mathrm{E} / \mathrm{Em}>15$. Stage III diastolic dysfunction (restrictive LV filling) was defined as E/A ratio $>1.5$ with a $\mathrm{DT}<150 \mathrm{~ms}$, mean $\mathrm{Em}<7 \mathrm{~cm} / \mathrm{s}$, and $\mathrm{E} / \mathrm{Em}>15$ (Khouri et al 2004; Nagueh et al 1997; Ommen et al 2000).
Statistical analysis

To compare TDI mean values between patients and controls, the independent $t$-test was used. A $p$-value $<0.05$ was considered significant. All statistics were performed using SPSS (12.0.2) for Windows package (SPSS, Inc., Chicago, IL, USA).

\section{Results}

\section{Patient population}

The mean age of the patients was $32 \pm 7$ years, 6 were male. The clinical features of the MPS I patients studied are summarized in Table 1 . Patients 3 and 5 are brother and sister, and patients 4, 7, 8 and 9 are siblings.

\section{Clinical characteristics}

None of the patients had a history of palpitations, shortness of breath, chest pain or other symptoms of suspected cardiac origin. From a cardiovascular point of view, all patients were thus in NYHA class I. The presenting symptoms were joint stiffness in 6 patients (nos. 1, 4, 6, 7, 8 and 9), dysmorphy in 2 patients (nos. 2 and 3 ) and growth retardation in 1 patient (no. 5).

\section{Electrocardiographic abnormalities}

Apart from one patient (patient no. 2) with atrial tachycardia 218 beats/min with 2:1 atrioventricular block, right axis deviation, and electrocardiographic evidence of right ventricular hypertrophy (confirmed

Table 1 Clinical characteristics of MPS patients with the attenuated phenotype

\begin{tabular}{|c|c|c|c|c|c|c|c|c|c|c|}
\hline $\begin{array}{l}\text { Patient } \\
\text { number }\end{array}$ & $\begin{array}{l}\text { Age } \\
\text { (years) }\end{array}$ & Sex & $\begin{array}{l}\text { Weight } \\
(\mathrm{kg})\end{array}$ & $\begin{array}{l}\text { Height } \\
(\mathrm{cm})\end{array}$ & $\begin{array}{l}\alpha \text {-L-Iduronidase } \\
\text { activity }^{\mathrm{a}}\end{array}$ & $\begin{array}{l}\text { Urinary } \\
\text { GAGs }^{\mathrm{b}}\end{array}$ & $\begin{array}{l}\text { Joint } \\
\text { stiffness }\end{array}$ & $\begin{array}{l}\text { Corneal } \\
\text { clouding }\end{array}$ & Hepatosplenomegaly ${ }^{c}$ & $\begin{array}{l}\text { Age of } \\
\text { clinical symptoms } \\
\text { (years) }\end{array}$ \\
\hline 1 & 21 & M & 56 & 158 & 0.3 & 16.2 & + & + & + & 11 \\
\hline 2 & 22 & M & 37 & 140 & 0.0 & 74.7 & + & + & + & 0 \\
\hline 3 & 26 & $\mathrm{~F}$ & 50 & 150 & 0.0 & 49.5 & + & + & + & 0 \\
\hline 4 & 28 & M & 75 & 171 & 0.0 & 10.4 & + & + & - & 4 \\
\hline 5 & 31 & M & 71 & 165 & 0.0 & 22.6 & + & + & + & 3 \\
\hline 6 & 31 & $\mathrm{~F}$ & 52 & 158 & 0.0 & NA & + & + & - & 3 \\
\hline 7 & 32 & M & 71 & 166 & 0.0 & 11.5 & + & + & - & 4 \\
\hline 8 & 39 & $\mathrm{~F}$ & 68 & 157 & 0.0 & 13.9 & + & + & - & 4 \\
\hline 9 & 43 & M & 88 & 168 & 0.4 & NA & + & + & - & 4 \\
\hline
\end{tabular}

${ }^{\mathrm{a}} \mathrm{nmol} / \mathrm{h}$ per mg, normal range $25-90$.

${ }^{\mathrm{b}} \mathrm{mg} / \mathrm{mmol}$ creatinine, normal adult range $<12.2$.

${ }^{\mathrm{c}}$ On abdominal ultrasound examination. 
Table 2 Valvular echocardiographic data

\begin{tabular}{|c|c|c|c|c|c|c|c|c|c|}
\hline \multirow[t]{2}{*}{ Patient number } & \multicolumn{3}{|c|}{ Thickening (mm) } & \multicolumn{3}{|c|}{$\begin{array}{l}\text { Transvalvular peak (Beesley et al 2001) gradient } \\
(\mathrm{mmHg})\end{array}$} & \multicolumn{3}{|c|}{ Regurgitation (severity) } \\
\hline & Mitral & Aortic & Tricuspid & Mitral & Aortic & Tricuspid & Mitral & Aortic & Tricuspid \\
\hline 1 & 4.3 & 2.2 & 3.4 & $7.0(4.0)$ & $9.0(6.0)$ & $1.9(1.0)$ & Mod-E & Mild-C & Mild \\
\hline 2 & 5.7 & 4.3 & 6.2 & $9.8(6.0)$ & $23.0(15.0)$ & NA & Mod-E & Mild-C & Mod \\
\hline 3 & 4.7 & 2.2 & 2.7 & $8.7(3.0)$ & $9.7(5.0)$ & $4.1(1.8)$ & Mod-E & Mod-E & Mod \\
\hline 4 & 2.2 & 1.7 & 1.1 & $3.4(1.3)$ & $7.3(4.0)$ & NA & Mild-C & Mod-C & Trivial \\
\hline 5 & 6.3 & 3.2 & 2.0 & $5.3(3.0)$ & $8.8(5.0)$ & $1.9(0.8)$ & Mod-E & Mod-C & Mod \\
\hline 6 & 2.5 & 1.9 & 2.6 & $3.9(1.3)$ & $6.1(3.4)$ & $1.6(1.1)$ & Mod-E & Mod-C & Mild \\
\hline 7 & 2.8 & 1.8 & 2.5 & $2.8(1.3)$ & $8.4(3.4)$ & NA & Mild-C & Mod-C & Mild \\
\hline 8 & 2.8 & 2.0 & 1.7 & $3.2(1.5)$ & $11.0(6.0)$ & $1.2(0.6)$ & Mod-C & Mod-C & Trivial \\
\hline 9 & 2.2 & 2.1 & 2.1 & $5.7(2.3)$ & $27.0(16.0)$ & NA & Mod-E & Mod-C & Trivial \\
\hline
\end{tabular}

Abnormal values are printed in bold.

C, central jet; E, eccentric jet; Mod, moderate; NA, not available.

Normal valve thickness values are for mitral and tricuspid valve leaflets $<3.0 \mathrm{~mm}$ and for aortic valve leaflet $<2.0 \mathrm{~mm}$.

Normal pressure gradient values are for mitral valve mean gradient $<5.0 \mathrm{mmHg}$ and for aortic valve mean gradient $<7.0 \mathrm{mmHg}$.

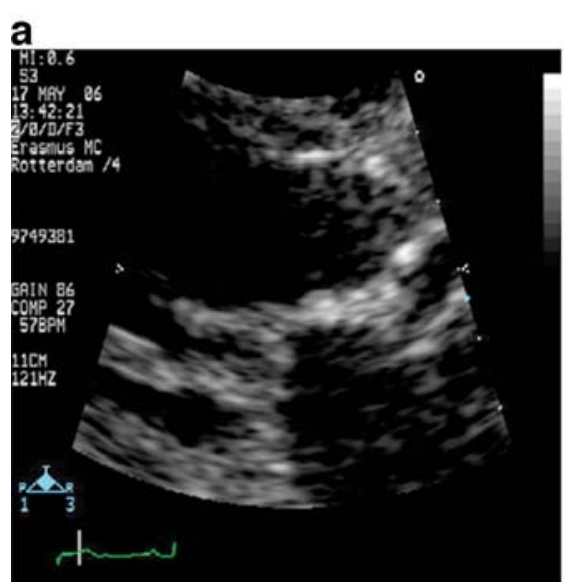

d

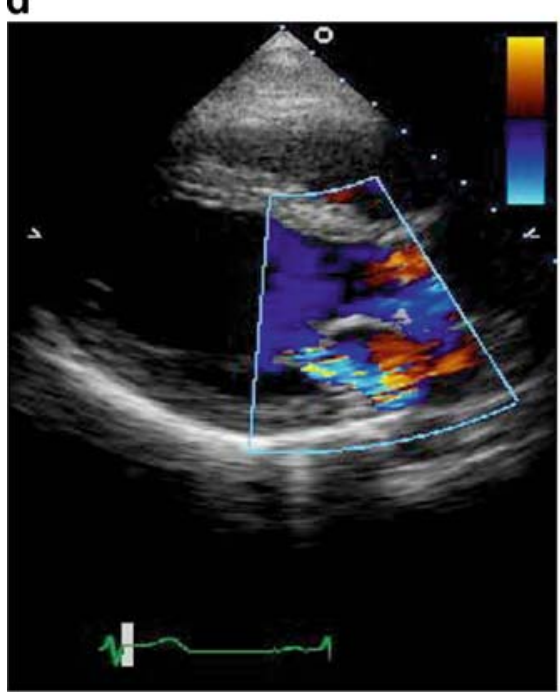

Fig. 1 Echocardiographic signs of cardiac involvement in patient (no. 1) with mucopolysaccharidosis type I: thickened mitral and aortic valve leaflets in parasternal long-axis view (A); thickened tricuspid valve leaflets in apical 4-chamber view (B); thickened mitral valve leaflets in parasternal short-axis view (C); mitral b

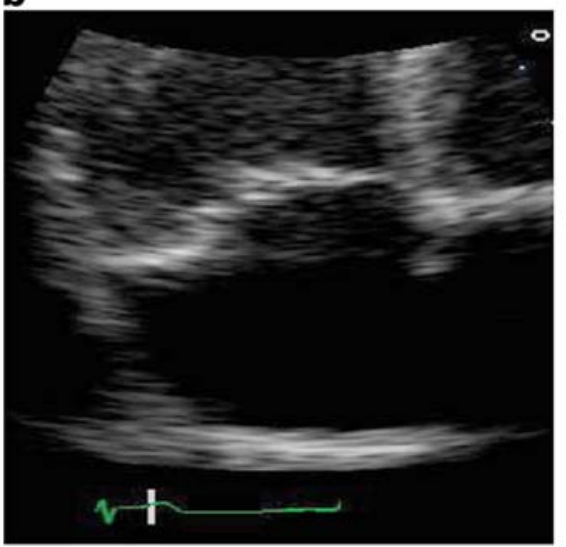

e

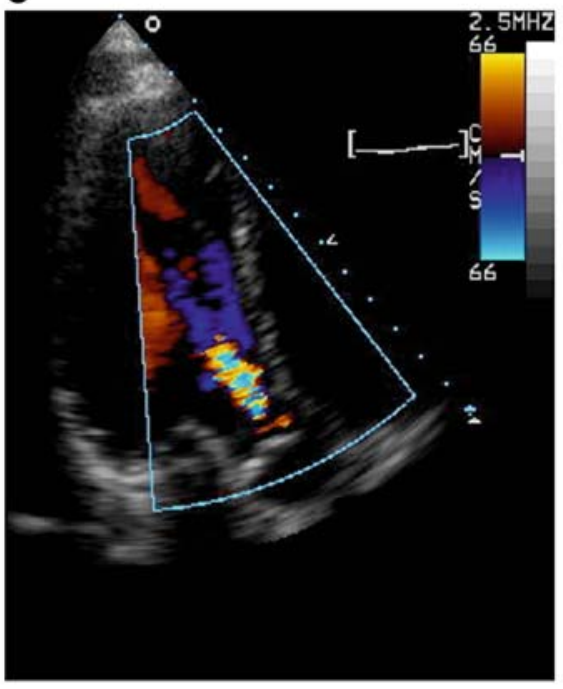

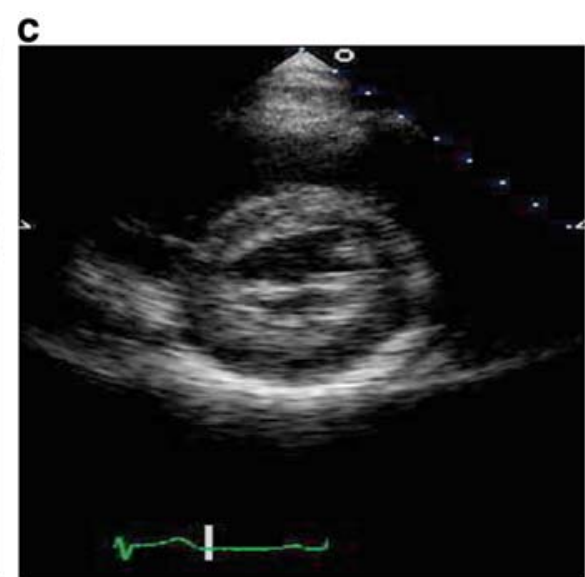

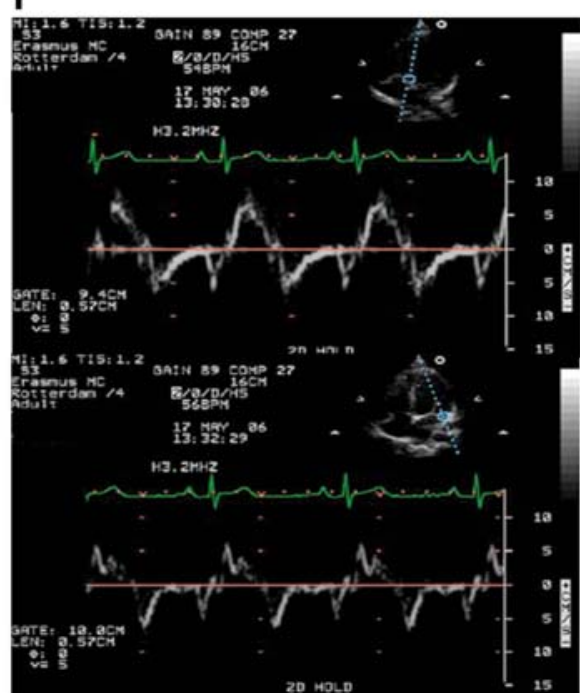

regurgitation jet in parasternal long-axis view (D); aortic regurgitation jet in apical long-axis view (E); and mitral annular velocity profile (F) from septal annulus (upper panel) and from lateral annulus (lower panel) 
Table 3 Functional echocardiographic data

\begin{tabular}{|c|c|c|c|c|c|c|c|c|}
\hline $\begin{array}{l}\text { Patient } \\
\text { number }\end{array}$ & $\begin{array}{l}\text { LA size } \\
(\mathrm{mm})\end{array}$ & $\begin{array}{l}\text { LV mass index } \\
\left(\mathrm{g} / \mathrm{m}^{2}\right)\end{array}$ & $\begin{array}{l}\text { LV-EDD } \\
(\mathrm{mm})\end{array}$ & $\begin{array}{l}\text { LV-EF } \\
(\%)\end{array}$ & $\begin{array}{l}\text { Diastolic } \\
\text { grade }\end{array}$ & $\begin{array}{l}\text { Mean Sm } \\
(\mathrm{cm} / \mathrm{s})\end{array}$ & $\begin{array}{l}\text { Mean } E_{m} \\
(\mathrm{~cm} / \mathrm{s})\end{array}$ & $\begin{array}{l}\text { Mean } \\
\text { E/E } E_{m} \text { ratio }\end{array}$ \\
\hline 1 & 38 & 127 & 52 & 69 & 0 & 6.0 & 7.0 & 14.5 \\
\hline 2 & 61 & 124 & 45 & 64 & II & NA & NA & NA \\
\hline 3 & 30 & 83 & 44 & 69 & 0 & NA & NA & NA \\
\hline 4 & 42 & 90 & 51 & 59 & 0 & 7.0 & 8.9 & 9.3 \\
\hline 5 & 33 & 86 & 46 & 69 & 0 & NA & NA & NA \\
\hline 6 & 37 & 94 & 45 & 67 & 0 & 5.2 & 8.1 & 12.3 \\
\hline 7 & 40 & 68 & 47 & 63 & 0 & 5.9 & 8.5 & 10.0 \\
\hline 8 & 33 & 65 & 44 & 57 & 0 & 6.0 & 7.0 & 11.6 \\
\hline 9 & 43 & 115 & 53 & 63 & II & 6.3 & 6.5 & 15.0 \\
\hline
\end{tabular}

Abnormal values are printed in bold.

LA, left atrial; LV, left ventricular; EDD, end-diastolic diameter; Sm, systolic mitral annular velocity; E, early filling wave of mitral inflow; $\mathrm{Em}=$ early diastolic mitral annular velocity. $\mathrm{NA}=$ not available.

Normal values in age- and sex-matched adults: LA size $<44 \mathrm{~mm}$; LV-EDD $<58 \mathrm{~mm}$; LV mass index in men $\leq 150 \mathrm{~g} / \mathrm{m}^{2}$, in women $\leq 120 \mathrm{~g} / \mathrm{m}^{2} ; \mathrm{LV}-\mathrm{EF}>50 \%$; mean $\mathrm{Sm}>7.7 \mathrm{~cm} / \mathrm{s}$; mean Em $>10.0 \mathrm{~cm} / \mathrm{s} ;$ E/Em ratio $<8$.

Grade II diastolic dysfunction means evidence for pseudo-normalization of LV filling pressure.

by a $7 \mathrm{~mm}$ thick mid right ventricular wall at echocardiography), no abnormalities were found on the 12-lead electrocardiography. All other 8 patients had normal sinus rhythm, electrical axis, conduction times, QRS complex and repolarization. During 24 h Holter monitoring, no further conduction abnormalities or arrhythmias were seen.

\section{Valvular function}

As seen in Table 2, aortic, mitral and tricuspid valve thickening was seen in, respectively, 5 (56\%), 4 $(44 \%)$, and $2(22 \%)$ patients. Mild mitral valve stenosis was seen in 1 patient and mild aortic stenosis in 2 patients. All patients had mild-to-moderate aortic and mitral valve regurgitation and 6 patients $(67 \%)$ had mild-to-moderate tricuspid valve regurgitation. Examples of echocardiographic abnormalities in patient 1 are displayed in Fig. 1.

Systolic function

As seen in Table 3, LV dimensions, ejection fraction and mass index were normal in all patients. Systolic mitral annular velocities were abnormal in all patients in whom these measurements were available; mean systolic mitral annular velocity in MPS patients was lower than in the normal control subjects $(6.1 \pm 0.6 \mathrm{vs}$ $9.1 \pm 1.4 \mathrm{~cm} / \mathrm{s}, p<0.01)$.

\section{Diastolic function}

As seen in Table 3, early diastolic mitral annular velocities were abnormal in all patients in whom these measurements were available; mean early diastolic mitral annular velocity in MPS patients was lower than in the normal control subjects $(7.8 \pm 0.9$ vs $13.3 \pm 3.3 \mathrm{~cm} / \mathrm{s}$, $p<0.01)$. When all three different diastolic dysfunction parameters were included (mitral inflow, pulmonary venous flow, and mitral annular velocity), two patients (nos. 2 and 9) had overt diastolic dysfunction (grade II or pseudo-normalization).

\section{Discussion}

Cardiovascular manifestations in children and adults with MPS I include arrhythmias (Vijay and Wraith 2005), atrioventricular heart block (Kakkis et al 2001), valvular involvement (Dangel 1998; Rigante and Segni 2002; Wippermann et al 1995) and hypertrophic cardiomyopathy (Dangel 1998; Mohan et al 2002; Rigante and Segni 2002). Valvular and muscular findings in studies and case reports that included MPS I patients with the attenuated form are summarized in Table 4. Unfortunately, only limited information is available on patients with the attenuated form of MPS I. As seen in Table 4, mild valvular thickening with stenosis and regurgitation was reported in most patients with the attenuated form of MPS I. Severe mitral or aortic stenosis necessitating surgery has been described in case reports (Butman et al 1989; Fischer et al 1999). In contrast, systolic LV function was described as normal in these patients (Braunlin et al 2006a,b; Dangel 1998; Fischer et al 1999; Minakata et al 1998; Mohan et al 2002; Sifuentes et al 2007).

In our study, 9 adult patients with the attenuated form of MPS I but without known manifestations of 
Table 4 Summary of studies that included patients with the attenuated form of MPS I

\begin{tabular}{|c|c|c|c|c|c|c|}
\hline \multirow[t]{2}{*}{ Authors (year) } & \multicolumn{3}{|c|}{ Patient numbers } & \multicolumn{3}{|c|}{ Attenuated form (Scheie) } \\
\hline & Hurler & Hurler-Scheie & Scheie & Valvular involvement & Muscle function & Muscle mass \\
\hline Sifuentes et al $(2007)^{\mathrm{a}}$ & 0 & 4 & 1 & Yes & $\leftrightarrow$ & - \\
\hline Braunlin $(2006 a, b)$ & 2 & 0 & 3 & Yes & $\leftrightarrow$ & - \\
\hline Vijay and Wraith (2005) & 0 & 19 & 10 & Yes & - & $\leftrightarrow$ \\
\hline Mohan et al (2002) & 29 & 0 & 2 & Yes & $\leftrightarrow$ & $\leftrightarrow$ \\
\hline Kakkis et al (2001) & 1 & 8 & 1 & Yes & - & - \\
\hline Fischer et al (1999) & 0 & 0 & 1 & Yes & $\leftrightarrow$ & $\leftrightarrow$ \\
\hline Dangel (1998) & 5 & 0 & 2 & Yes & $\leftrightarrow$ & $\leftrightarrow$ \\
\hline Minakata et al (1998) & 0 & 0 & 2 & Yes & $\leftrightarrow$ & $\uparrow$ \\
\hline Wippermann et al (1995) & 12 & 0 & 6 & Yes & - & - \\
\hline Masuda et al (1993) & 0 & 0 & 1 & Yes & - & - \\
\hline Butman et al (1989) & 0 & 0 & 1 & Yes & - & - \\
\hline Tada et al (1983) & 0 & 0 & 1 & Yes & - & - \\
\hline Fujiwara et al (1983) & 0 & 0 & 1 & Yes & - & - \\
\hline
\end{tabular}

$\leftrightarrow$, normal; $\uparrow$, increased; - , data are not available.

${ }^{a}$ Long-term follow-up of the series by Kakkis et al (2001).

cardiac abnormalities were studied. Mild-to-moderate valvular regurgitation was seen in all patients, in particular of the aortic and mitral valves. Most patients had also evidence for valvular thickening; significant gradients were seen in 3 patients. These findings are consistent with previously published data (Dangel 1998; Rigante and Segni 2002). In histological studies in mice, enlarged and misshapen heart valves containing large numbers of highly vacuolated interstitial cells have been described (Jordan et al 2005). Despite normal LV ejection fraction, we describe for the first time subclinical systolic and diastolic LV dysfunction. This was evidenced by reduced systolic and early diastolic mitral annular velocities reflecting impaired longitudinal LV function. Abnormal systolic longitudinal LV function is an early marker for LV dysfunction and may be present at stages in which radial function may be normal or even compensatorily increased in the early stages of disease (Marwick 2004). We and others have reported early signs of systolic LV dysfunction in patients with diabetes, hypertension and storage or neuromuscular diseases (Marwick 2004; Poulsen et al 2003; Vydt et al 2007) Of note, none of our patients had diabetes or hypertension. Thus far, systolic LV myocardial involvement has been described only in patients with the severe MPS Hurler syndrome (Dangel 1998; Mohan et al 2002). In severely affected mice, infiltration of cardiac muscle by storage-laden cells has been shown histologically (Jordan et al 2005). Also, diastolic function seems abnormal in our MPS I patients with the attenuated phenotype, as evidenced by abnormal
Em velocity and increased E/Em ratios, corresponding to increased LV filling pressures (Nagueh et al 1997; Ommen et al 2000). Of note, most patients had mildto-moderate mitral regurgitation and this may be a confounding factor in the assessment of E/Em ratio. However, it was shown that in primary mitral regurgitation (due to intrinsic valvular disease such as in MPS I), in contrast to secondary mitral regurgitation (caused by LV and/or mitral annular enlargement), the $\mathrm{E} / \mathrm{Em}$ ratio is not significantly increased (Bruch et al 2004).

\section{Limitations}

Echocardiographic measurement of valvular thicknesses is difficult, and literature-derived normal values are heterogeneous. Usually, mitral and tricuspid leaflet thickness $>3 \mathrm{~mm}$ is considered abnormal in both transthoracic and transoesophageal echocardiography (Crawford and Roldan 2001; Weissman et al 1994). The measured thickness may be greater than the actual thickness because of the gain settings, poor resolution in the far field, the ultrasound transit time being slower in the dense, fibrocalcific structures than in soft tissue, and the ultrasound frequency. Although the thickness of the anterior mitral leaflet, particularly its middle part, can be measured relatively easily by two-dimensional echocardiography, the thickness of the posterior leaflet may be more difficult to measure because of the shortness of the leaflet and the numerous attachments of the chordae tendineae (Sahasakul et al 1988). 


\section{Conclusion}

MPS I patients with the attenuated phenotype have, apart from valvular abnormalities, also LV diastolic and systolic abnormalities. Currently, no information is available about the progression in time of these diastolic and systolic abnormalities. Until such data are available, routine TDI measurements cannot be recommended. Nevertheless, all MPS I patients with the attenuated phenotype should undergo a baseline echocardiographic examination, and until specific information about cardiac disease progression is available should be followed-up according to the available (valvular) guidelines since the described cardiac abnormalities may have important therapeutic and prognostic consequences (Zoghbi et al 2003).

\section{References}

Beesley CE, Meaney CA, Greenland G, et al (2001) Mutational analysis of 85 mucopolysaccharidosis type I families: frequency of known mutations, identification of 17 novel mutations and in vitro expression of missense mutations. Hum Genet 109(5): 503-511.

Braunlin E, Mackey-Bojack S, Panoskaltsis-Mortari A, et al (2006a) Cardiac functional and histopathologic findings in humans and mice with mucopolysaccharidosis type I: implications for assessment of therapeutic interventions in Hurler syndrome. Pediatr Res 59(1): 27-32.

Braunlin EA, Berry JM, Whitley CB (2006b) Cardiac findings after enzyme replacement therapy for mucopolysaccharidosis type I. Am J Cardiol 98(3): 416-418.

Bruch C, Stypmann J, Gradaus R, Breithardt G, Wichter T (2004) Usefulness of tissue Doppler imaging for estimation of filling pressures in patients with primary or secondary pure mitral regurgitation. Am J Cardiol 93(3): 324-328.

Butman SM, Karl L, Copeland JG (1989) Combined aortic and mitral valve replacement in an adult with Scheie's disease. Chest 96(1): 209-210.

Cheitlin MD, Alpert JS, Armstrong WF, et al (1997) ACC/AHA guidelines for the clinical application of echocardiography: executive summary. A report of the American College of Cardiology/American Heart Association Task Force on practice guidelines (Committee on Clinical Application of Echocardiography) Developed in collaboration with the American Society of Echocardiography. $\mathrm{J} \mathrm{Am}$ Coll Cardiol 29(4): 862-879.

Crawford MH, Roldan CA (2001) Quantitative assessment of valve thickness in normal subjects by transesophageal echocardiography. Am J Cardiol 87(12): 1419-1423.

Dangel JH (1998) Cardiovascular changes in children with mucopolysaccharide storage diseases and related disorders-clinical and echocardiographic findings in 64 patients. Eur J Pediatr 157(7): 534-538.

Fischer TA, Lehr HA, Nixdorff U, Meyer J (1999) Combined aortic and mitral stenosis in mucopolysaccharidosis type I-S (Ullrich-Scheie syndrome). Heart 81(1): 97-99.

Fujiwara S, Miyamoto Y, Umemoto M, et al (1983) [Echocardiographic findings in 3 cases of mucopolysaccharidosis]. J Cardiogr 13(1): 171-180. [In Japanese].
Jordan MC, Zheng Y, Ryazantsev S, Rozengurt N, Roos KP, Neufeld EF (2005) Cardiac manifestations in the mouse model of mucopolysaccharidosis I. Mol Genet Metab 86(1-2): 233-243.

Kakkis ED, Muenzer J, Tiller GE, et al (2001) Enzymereplacement therapy in mucopolysaccharidosis I. $N$ Engl $J$ Med 344(3): 182-188.

Khouri SJ, Maly GT, Suh DD, Walsh TE (2004) A practical approach to the echocardiographic evaluation of diastolic function. J Am Soc Echocardiogr 17(3): 290-297.

Lang RM, Bierig M, Devereux RB, et al (2006) Recommendations for chamber quantification. Eur J Echocardiogr 7(2): 79-108.

Marwick TH (2004) Tissue Doppler imaging for evaluation of myocardial function in patients with diabetes mellitus. Curr Opin Cardiol 19(5): 442-446.

Masuda H, Morishita Y, Taira A, Kuriyama M (1993) Aortic stenosis associated with Scheie's syndrome. Report of successful valve replacement. Chest 103(3): 968-970.

Minakata K, Konishi Y, Matsumoto M, Miwa S (1998) Surgical treatment for Scheie's syndrome (mucopolysaccharidosis type I-S): report of two cases. Jpn Circ J 62(9): 700-703.

Mohan UR, Hay AA, Cleary MA, Wraith JE, Patel RG (2002) Cardiovascular changes in children with mucopolysaccharide disorders. Acta Paediatr 91(7): 799-804.

Nagueh SF, Middleton KJ, Kopelen HA, Zoghbi WA, Quinones MA (1997) Doppler tissue imaging: a noninvasive technique for evaluation of left ventricular relaxation and estimation of filling pressures. J Am Coll Cardiol 30(6): 1527-1533.

Nelson J, Shields MD, Mulholland HC (1990) Cardiovascular studies in the mucopolysaccharidoses. J Med Genet 27(2): 94-100.

Neufeld E, Muenzer J (2001) The mucopolysaccharidoses. In: Scriver CR, Beaudet AL, Sly WS, Valle D, eds; Childs B, Kinzler KW, Vogelstein B, assoc. eds. The Metabolic and Molecular Bases of Inherited Disease, 8th edn. New York: McGraw-Hill, 3421-3452.

Nikitin NP, Witte KK, Thackray SD, de Silva R, Clark AL, Cleland JG (2003) Longitudinal ventricular function: normal values of atrioventricular annular and myocardial velocities measured with quantitative two-dimensional color Doppler tissue imaging. J Am Soc Echocardiogr 16(9): 906-921.

Ommen SR, Nishimura RA, Appleton CP, et al (2000) Clinical utility of Doppler echocardiography and tissue Doppler imaging in the estimation of left ventricular filling pressures: a comparative simultaneous Doppler-catheterization study. Circulation 102(15): 1788-1794.

Otto CM (2004) Textbook of Clinical Echocardiography. Philadelphia: Elsevier Saunders.

Poulsen SH, Andersen NH, Ivarsen PI, Mogensen CE, Egeblad H (2003) Doppler tissue imaging reveals systolic dysfunction in patients with hypertension and apparent isolated diastolic dysfunction. J Am Soc Echocardiogr 16(7): 724-731.

Rigante D, Segni G (2002) Cardiac structural involvement in mucopolysaccharidoses. Cardiology 98(1-2): 18-20.

Sahasakul Y, Edwards WD, Naessens JM, Tajik AJ (1988) Agerelated changes in aortic and mitral valve thickness: implications for two-dimensional echocardiography based on an autopsy study of 200 normal human hearts. Am J Cardiol 62(7): 424-430.

Sifuentes M, Doroshow R, Hoft R, et al (2007) A follow-up study of MPS I patients treated with laronidase enzyme replacement therapy for 6 years. Mol Genet Metab 90(2): 171-180. 
Tada A, Tanaka A, Yasuda M, et al (1983) [Cardiac manifestation of the mucopolysaccharidoses: periodical echocardiographic evaluation in six cases]. $J$ Cardiogr 13(2): 407-423. [In Japanese].

Vijay S, Wraith JE (2005) Clinical presentation and follow-up of patients with the attenuated phenotype of mucopolysaccharidosis type I. Acta Paediatr 94(7): 872-877.

Vydt TC, de Coo RF, Soliman OI, et al (2007) Cardiac involvement in adults with m.3243A $>\mathrm{G}$ MELAS gene mutation. Am J Cardiol 99(2): 264-269.
Weissman NJ, Pini R, Roman MJ, Kramer-Fox R, Andersen HS, Devereux RB (1994) In vivo mitral valve morphology and motion in mitral valve prolapse. Am J Cardiol 73(15): 1080-1088.

Wippermann CF, Beck M, Schranz D, Huth R, Michel-Behnke I, Jungst BK (1995) Mitral and aortic regurgitation in 84 patients with mucopolysaccharidoses. Eur J Pediatr 154(2): 98-101.

Zoghbi WA, Enriquez-Sarano M, Foster E, et al (2003) Recommendations for evaluation of the severity of native valvular regurgitation with two-dimensional and Doppler echocardiography. J Am Soc Echocardiogr 16(7): 777-802. 